\title{
La Igualdad en la Revuelta Educativa: una conversación con Jacques Rancière
}

\author{
Facundo Giuliano' \\ María Natalia Cantarelli"
}

'Instituto de Investigaciones en Ciencias de la Educación, Facultad de Filosofía y Letras, Universidad de Buenos Aires - Argentina "Instituto de Filosofía Dr. Alejandro Korn, Facultad de Filosofía y Letras, Universidad de Buenos Aires - Argentina

Entre los filósofos de su generación Jacques Rancière es, probablemente, uno de los que ha ofrecido mayor cantidad de entrevistas a interlocutores de los más variados ámbitos ${ }^{1}$. Esta disposición, que desborda los formatos académicos, echa raíces en el corazón mismo de su obra: la afirmación de que no hay un lugar propio del pensamiento, ya que, muy por el contrario, el pensamiento trabaja en todas partes.

Esta conversación elige explorar el lugar que la educación ocupa en la filosofía de Rancière, aunque no pretende hacerlo de manera concluyente. Además de ofrecer una puerta de entrada a la lectura en clave educativa de la obra de este autor, la conversación busca detenerse en algunos sentidos aparentemente evidentes, aunque necesariamente polémicos, del pensamiento educativo: ¿Qué vínculos podemos trazar entre educación y filosofía? ¿Cómo abordar la relación del magisterio con la institución? ¿Qué tipo de comunidad es la comunidad educativa? ¿Qué entendemos por escuela democrática? Son algunas de las inquietudes que motorizan la conversación.

El pensamiento de Rancière es un pensamiento indisciplinado, es decir, se caracteriza por el constante desplazamiento de las fronteras disciplinares y sus lógicas de legitimación. En ese sentido, Rancière no aporta un análisis filosófico al campo educativo o político. Antes bien,

Educação \& Realidade, Porto Alegre, v. 41, n. 2, p. 613-627, abr./jun. 2016. 613 http://dx.doi.org/10.1590/2175-623662526 
La Igualdad en la Revuelta Educativa

cada uno de sus textos y cada una de sus entrevistas expresan un esfuerzo orientado a romper tales compartimentaciones, mediante maneras de hacer y decir difíciles de clasificar desde las coordenadas académicas.

Desde sus textos más tempranos Rancière se pregunta por la educación en la que él y su generación se formaron. Textos tales como $L a$ lección de Althusser, La noche de los proletarios, El filósofo y sus pobres y El maestro ignorante, ofrecen un temprano balance (auto)crítico de esa formación, definitivamente perturbada por las revueltas estudiantiles de 1968 y su cuestionamiento a la autoridad fundada en el saber. Así, su obra encarna una reflexión profunda sobre las condiciones de enunciación de la palabra sabia y su impacto en la esfera política.

Sobre estas inquietudes echa raíces el análisis ranciereano del poder (pedagógico) fundado en la desigualdad primordial entre sabios e ignorantes. Su puesta en cuestión de la categoría de "desconocimiento" que la tradición marxista legó a los análisis sociológicos de la institución escolar bajo la forma de la illusio, constituye un pilar central de la elaboración ranciereana de la ignorancia como potencia igualitaria. La ignorancia ranciereana entraña un gesto emancipado: el de ensayar maneras de hacer y decir que guiadas escapen a - es decir, ignoren - la distribución jerárquica de lugares y funciones con las que el "orden pedagógico" clasifica cuerpos e (in)capacidades.

Rancière toma de Joseph Jacotot la idea de que la igualdad no es el principio de la comunidad, ni tampoco una propiedad de los cuerpos. Muy por el contario, la igualdad de los seres de palabra - que es la "igualdad de las inteligencias" - constituye un postulado práctico. En tanto tal, la igualdad no se posee sino que se declara. De modo que una declaración de igualdad no es un enunciado descriptivo al que pueda atribuírsele cierto valor de verdad, sino más bien un enunciado performativo cuya potencia práctica indeterminada conviene explorar.

Esta concepción de la igualdad interpela de manera directa lo que en sus textos más tempranos Rancière caracteriza como la lógica desigualitaria del "poder profesoral”; un poder que funda la relación de los actos intelectuales de enseñar y aprender sobre la desigualdad radical entre conocimiento y desconocimiento. Esto implica, para Rancière, que todo conocimiento es dos cosas a la vez: un corpus de saberes y una distribución de espacios. Es preciso entonces abandonar el dominio de los condicionamientos sociales, para concentrarnos con Rancière en la cuestión de la igualdad y los efectos de su declaración sobre la distribución de espacios de la sociedad tecnocrática. En definitiva, es preciso instalar la pregunta por el poder performativo del postulado igualitario en el orden pedagógico.

La figura del maestro ignorante es el contrapunto perfecto de la figura del experto. Postula que la función magisterial puede desanclarse de toda institución, es decir, de la distribución de espacios y lugares 
que el saber configura. En ese sentido, el maestro ignorante constituye en sí mismo un postulado igualitario, ya que es la afirmación de que cualquiera puede enseñar. Decir, como hemos dicho al inicio, que no hay un lugar propio del pensamiento implica decir que entre la función del maestro ignorante y la del experto, hay una tensión ineludible. Esta tensión, expresada en la idea de emancipación intelectual, constituye el pulso del pensamiento ranciereano: un acto insurreccional destinado a derrocar la más radical de las tiranías, la que declara a los seres humanos incapaces de concebirse enteramente como seres pensantes.

\section{Institución, Magisterio e Igualdad de las Inteligencias}

Querido Jacques, deteniéndonos en tu experiencia, ¿Qué significa - o ha significado - para ti ser docente o profesor?

Jacques Rancière: Debo decir que durante mucho tiempo sufrí una tensión entre mi trabajo como investigador y mi trabajo como enseñante. Sólo hacia el final de mi carrera docente experimenté el beneficio que podía constituir la obligación de tener que dar, semana tras semana, una formulación precisa de los resultados de mi trabajo. En París VIII, universidad donde me desempeñé como profesor, había una gran variedad de estudiantes y muchos de ellos no buscaban allí un diploma. Esto nos enfrentaba a un público sumamente diverso, que no podría sintetizarse como el conjunto de estudiantes que seguía un curso determinado. Esa circunstancia me condujo a sostener un principio: no distinguir niveles.

Con respecto a los efectos de a mi enseñanza, he aprendido que no era necesario esperar que éstos fueran inmediatos. Esto me permitió verificar que aquellos y aquellas que más han aprendido de mí, aquellos y aquellas que han sentido el efecto de mi palabra más vívidamente, han sido frecuentemente personas que nunca tuve como estudiantes, gente que me había escuchado libremente o que simplemente me había leído, muchas veces a través de una traducción, y muy lejos de los lugares donde yo he enseñado. Todo ello resulta coherente con la idea de emancipación intelectual: siempre hay una tensión entre la función del profesor y la del maestro emancipador. Siempre emancipamos mejor a aquellas personas que no tienen ningún vínculo de dependencia con nosotros.

Uno de los aportes más significativos de tu filosofía en el campo de la reflexión educativa radica en la posibilidad de pensar un "magisterio sin institución". Esto introduce el problema de la autoridad igualitaria. ¿Cómo concibes la construcción de la autoridad de maestros y profesores? ¿Qué relación puedes establecer entre esa construcción y el marco de las instituciones educativas contemporáneas en el que se desarrolla la función docente?

J.R.: "Un magisterio sin institución" quiere decir, en primer lugar, que cualquier persona o cualquier cosa pueden ejercer la función de maes- 
La Igualdad en la Revuelta Educativa

tro para cualquiera y, más precisamente, que pueden ejercer la función de maestro ignorante. El maestro ignorante es aquel que nos pone en movimiento y nos hace aprender lo que él mismo no sabe, en la medida en que su autoridad nos conduce a un punto que ni él ni nosotros conocemos con anterioridad. Es allí donde podemos verificar la igualdad de las inteligencias ${ }^{3}$. En la versión contraria, el profesor es por definición el que sabe hacia dónde conducir al ignorante en la progresión de los saberes que reproduce la relación desigual. Ahora bien, un profesor puede ejercer la función de maestro ignorante siempre y cuando separe las funciones del sabio y del maestro, funciones que la lógica de la institución busca confundir.

Respecto a tu concepción de la "igualdad de las inteligencias"4 que planteas, ¿En qué se diferencia de la concepción liberal de "igualdad de oportunidades", tan cara al campo educativo?

J.R.: La igualdad de oportunidades es una regla institucional que separa los criterios discriminadores operantes en el encuentro de grupos o categorías tradicionalmente desfavorecidas. La igualdad de inteligencias es algo completamente distinto. No es una regla institucional. Es un axioma que planteamos y que nos esforzamos en verificar. No dice: todos los estudiantes son iguales sean blancos o negros, masculinos o femeninos, etc. Sólo demanda a los que se dirigen a esos estudiantes hacerlo según la presuposición de que tienen la misma inteligencia que ellos.

En El método de la igualdad ${ }^{5}$ repasas tu trayectoria educativa y mencionas el momento en que descubriste "esas extrañas leyes de los exámenes y concursos" y "su carácter ritual de entronización y humillación". También has comentado que en los comienzos de París VIII los exámenes no constituían una instancia obligatoria. ¿Cómo consideras hoy a la lógica evaluadora dominante?

J.R.: En El método de la igualdad yo me referí precisamente al hecho de que los exámenes y concursos destinados a seleccionar a las "élites" hacían sentir a los elegidos que debían su entronización a la benevolencia de los examinadores, más que a su propio mérito. En ello se refleja un rasgo particular de la lógica desigualitaria, la cual siempre tiende a inferiorizar aquello que ella misma distingue. De modo que el examen, como un aspecto propio de esa lógica desigualitaria, constituye una limitación inherente a la institución.

En Paris VIII también había exámenes, pero el departamento de filosofía al que yo pertenecía decidió eliminarlos. Más tarde sus diplomas fueron invalidados. Si bien con el tiempo su valor fue restablecido, todavía quedan por debajo en la jerarquía de diplomas. Por eso los estudiantes que vienen a hacer filosofía a París VIII deben amar la filosofía por sí misma y renunciar a la idea de hacer carrera con ella. Hoy mucho más que ayer los estudiantes "normales" consideran a las universidades como usinas de diplomas. Es así que muestran a los enseñantes un

616 Educação \& Realidade, Porto Alegre, v. 41, n. 2, p. 613-627, abr./jun. 2016. 
desprecio evidenciado en la distancia con la que se conducen, acorde a la lógica de "inferiores/superiores" analizada por Jacotot. Una vez más esto nos conduce a afirmar que las instituciones no tienen la vocación de emancipar y es siempre separándonos de su lógica normal que podemos introducir maneras de enseñar y aprender acordes al método de la igualdad.

En territorios como América Latina, donde la colonización ha dejado su huella, la colonización pedagógica ha sido un factor clave en lo que ciertos referentes postcoloniales o de-coloniales llaman "epistemicidio" o "colonialidad del saber". ¿Cuál es tu mirada respecto a esta problemática que hoy se verifica, entre otras cosas, en la reducción de la educación a estándares de calidad internacional? ${ }^{6}$

J.R.: No estoy seguro de que podamos pensar esta cuestión [sólo] en los términos de la problemática postcolonial. El efecto de agresión producido por los criterios de evaluación internacionales (como por ejemplo las pruebas PISA) se ejerce también a través de los sistemas educativos de la vieja Europa. Hay, en este dominio, como en muchos otros, una coerción ejercida por las instituciones internacionales. Esta coerción es llevada adelante en nombre de normas deducidas de ciertas ciencias, cuyo poderío se ha establecido haciendo prevalecer un cierto tipo de saber internacionalizado y uniformado (economía neoliberal, ciencias cognitivas, ciencias del lenguaje, filosofía analítica, ciencias didácticas, etc.). Todo esto hace que el problema de sostener saberes y formaciones no alineadas en torno de esas normas se presente en todas partes, aunque específicamente pueda inscribirse como la prolongación de una herencia colonial en ciertos países.

\section{Una Educación In-disciplinada}

En numerosos textos afirmas que una "experiencia estética" es aquella que escapa a la distribución sensible de los lugares y de las competencias que estructuran lo social, en tanto tal experiencia neutraliza la relación circular del conocimiento como saber y como distribución de espacios. En este tipo de experiencia se juega lo que caracterizas como "pensamiento in-disciplinario", es decir, un pensamiento que ignora las fronteras de las disciplinas para conferir a los discursos el estatus de armas de una querella. En contraposición a las experiencias educativas tecnocráticas basadas en objetivos prefijados o competencias a adquirir, y en la concepción disciplinaria del saber, ¿consideras que la función docente puede introducir en los espacios educativos maneras de hacer y decir vinculadas a la experiencia estética y al pensamiento in-disciplinario?

J.R.: Este problema nos acerca a una cuestión: la de la posibilidad de preservar zonas de indeterminación en el seno del sistema escolar caracterizado por la compartimentación de saberes y la progresión jerarquizada de los aprendizajes. Existe todavía bastante indeterminación 
La Igualdad en la Revuelta Educativa

en el contenido de ciertas disciplinas, indeterminación que permite practicar la indisciplinariedad a los enseñantes que así lo deseen, solos o en cooperación con otros. Dicho eso, debemos advertir que el orden pedagógico busca ocupar esas zonas para imponer la interdisciplinariedad, es decir, el recorte de la enseñanza en temas sobre los cuales cada disciplina está llamada a aportar su contribución. Es necesario contraponer la indisciplinariedad a esa interdisciplinariedad que, en rigor, no es otra cosa que un paso más en la saturación del espacio de aprendizaje a través de la distribución oficial de los saberes y de sus modos de adquisición.

La noción de "reparto de lo sensible" ocupa un lugar destacado en tu reflexión estética. En términos generales, con "reparto de lo sensible" designas un orden de lo visible y lo decible que constituye la regla del aparecer de los cuerpos y sus maneras de hacer. Esto (te) permite analizar la relación dinámica entre dos regímenes sensibles opuestos que conforman ese reparto: por un lado, un régimen de distribución jerárquica que clasifica lugares y capacidades y fija un horizonte de posibles (al que denominas policía); y por otro lado, un régimen de perturbación y desclasificación de dicha distribución (al que denominas politica). En tiempos en que la mirada pedagógica se torna primordialmente evaluadora, fijando fronteras entre categorías y señalando quienes "pertenecen" según materialicen o no la norma, ¿qué importancia le reconoces a la mirada en los espacios educativos? Y más específicamente, ¿puede concebirse a estos espacios como repartos sensibles factibles de ser alterados o perturbados??

J.R.: Para empezar a responder esta pregunta deberíamos precisar si nos referimos a la mirada en sentido propio o figurado. Si se piensa en términos de reparto de lo sensible, se puede decir que hay una relación fuerte entre tres tipos de mirada: la mirada como percepción sensible y como atención a aquello que se nos da a la vista; la mirada como manera en la cual nuestro espíritu se relaciona con el mundo en el que vive; y la mirada como consideración que tenemos de los otros. La lógica desigualitaria dominante nos enseña a desconfiar de la experiencia sensible y a buscar lo que yace detrás o debajo de las cosas. Esta lógica nos transforma en "incrédulos" que "leen" las imágenes y presumen de no dejarse engañar por las apariencias. Hubo tiempos en los que un pensamiento de este tipo pudo ser considerado subversivo. Hoy podemos darnos cuenta de que ese pensamiento es el mejor modo de hacernos cómplices del orden existente. En El Maestro Ignorante he denominado a esta lógica "la sociedad del desprecio" ${ }^{8}$. Según ella, el dominado adhiere al orden dominante en la medida en que le permite jugar el juego del espíritu fuerte que sabe lo que esconden las apariencias de la igualdad. Oponerse a esta lógica implica sin duda otra educación de la mirada en el sentido más material: en un mundo donde todo espectáculo y toda imagen es a priori "leída”, interpretada y transformada en su significado, conviene devolver a la mirada la posibilidad de mirar efectivamente lo que es dado a los ojos, la posibilidad de tener confianza en una cier-

618 Educação \& Realidade, Porto Alegre, v. 41, n. 2, p. 613-627, abr./jun. 2016. 
ta igualdad de lo visible. Es así como yo interpretaría personalmente el tema deleuziano de la necesidad de creer de nuevo en el mundo ${ }^{9}$. Una contra-educación que devuelve a la experiencia sensible su materialidad es sin duda la condición previa de las actitudes que ofrecen confianza a los otros y hacen posible la construcción de mundos en común. Teniendo en cuenta el carácter masivo de los sujetos que involucra el campo educativo y la multiplicidad de suelos que gravitan tus reflexiones éticas, estéticas, epistémicas y políticas: ¿cuál consideras que es el problema más urgente de este campo?

J.R.: Está claro que no existe una respuesta unívoca a esta pregunta. Hay procesos educativos que apuntan a la adquisición de un saber-hacer específico y no pueden ser juzgados más que por los hechos. Hoy podemos ver el intento de generalizar ese modelo de proceso educativo definiendo ciertas competencias cuya transmisión y adquisición sea verificable $^{10}$. Es evidente que ese modelo no cubre más que una parte limitada de las formas de educación y de las capacidades que esas formas producen.

No obstante ello, no me satisfacen las respuestas que a ese modelo oponen el aprendizaje problemático de una "cultura general” o de un "espíritu crítico" orientado a la formación de ciudadanos iluminados y responsables. Esa cultura general es frecuentemente muy provincialy ese espíritu crítico se nutre de muchos prejuicios y estereotipos. De modo que la pregunta no debe plantearse en esos términos, es decir, no debemos preguntarnos por lo que el sistema escolar debe hacer. Este tipo de planteos conducen inevitablemente a un sinnúmero de reformas y programas elaborados por comisiones ministeriales, cuya función esencial es la autolegitimación del sistema. Esto nos reconduce a la cuestión recién planteada. Es necesario formular el problema a la inversa: ¿cómo conservar, en el seno de esta máquina de autorreproducción que es el sistema escolar, tiempos y espacios libres sustraídos de los objetivos previamente definidos, tiempos y espacios libres que permitan a los actores - enseñantes y estudiantes - inventar dispositivos y trayectorias originales que los habiliten a conocer, en términos de Jacotot, la "cosa con la que relacionar todo el resto"? ${ }^{11}$

Conservar esos espacios y esos tiempos implica inventar experiencias a partir de las cuales cada uno pueda tomar conciencia de su condición de ser inteligente, es decir, cada uno pueda tomar posesión de la misma inteligencia y las mismas capacidades de percibir y de sentir que todos los demás. La lógica propia del aprendizaje de la cosa singular que hace posible la revelación de una capacidad ante sí misma, es antinómica con respecto a la lógica de la institución escolar. No obstante, esa lógica antinómica constituye un círculo que siempre puede cortar la lógica institucional en puntos singulares. El problema fundamental es, por lo tanto, mantener la posibilidad de esos puntos de encuentro entre lógicas opuestas.

Educação \& Realidade, Porto Alegre, v. 41, n. 2, p. 613-627, abr./jun. 2016. 
La Igualdad en la Revuelta Educativa

\section{Discontinuidades Igualitarias entre Enseñar y Aprender}

En El desacuerdo ${ }^{12}$ presentas a la filosofía política como el conjunto de operaciones mediante las cuales la filosofía trata de terminar con la política, entendida esta como la actividad cuyo principio es la igualdad. Si concebimos a la educación como una actividad guiada por el postulado de la "igualdad las inteligencias", ¿podríamos pensar que el vínculo entre filosofía y educación comporta elementos similares a los que caracterizan la relación entre filosofía y política?

J.R.: La lógica educativa ordinaria parte de la postulación de la desigualdad y, por lo tanto, constituye una lógica de verificación de la desigualdad. Este es el modelo que ha inspirado a la filosofía de Platón y su intento de acabar con la política. Acabar con la política significa suprimir la presuposición igualitaria inherente a la idea de comunidad política; y con comunidad política aquí nos referimos a la comunidad que no se funda en la distinción entre la capacidad de gobernar y la capacidad que ser gobernado. Con Platón, la filosofía contrapone el modelo educativo a la idea democrática. Esta operación conlleva un juego sutil entre filosofía y educación. Platón rechaza a los educadores porque considera que la virtud no se enseña, que el filósofo no transmite ningún saber y que, en última instancia, el saber en sí mismo no es algo que se transmita. Para ello configura a su manera una escena de "igualdad de las inteligencias" (sintetizada en el "descubrimiento" de un teorema matemático por parte del esclavo de Menón) ${ }^{13}$. En esa escena vemos cómo el rechazo platónico de la transmisión está destinado a afirmar una desigualdad radical: se trata de descalificar a los enseñantes ordinarios, o más precisamente, a aquellos que permanecen en una relación de exterioridad con respecto al saber. Como contrapartida a este rechazo, Platón preserva una figura del maestro en la que el saber no es separable a la persona. Esta figura constituye, en definitiva, una manera de ser de la cual debemos impregnarnos para lograr que se imprima en nosotros. La filosofía tal como se practica hoy en día es todavía heredera de ese doble juego entre la desigualdad de las inteligencias y el sistema educativo que esa presuposición organiza.

En El malestar en la estética ${ }^{14}$ presentas los principales aspectos e implicancias de lo que identificas como "comunidad politica" y "comunidad ética". Allí señalas que una comunidad política es una comunidad estructuralmente dividida en relación consigo misma. Tal división da cuenta de una forma de simbolización de lo común y sus partes, que siempre es litigiosa. El intento de borrar el trazado de esa división (que inevitablemente tropieza con un resto problemático) hace de la comunidad política una comunidad ética. ¿Con cuál de estas dos ideas de comunidad analizarías lo que habitualmente denominamos "comunidad educativa"?

J.R.: No deseo introducir dicotomías por doquier entre la política y la ética o entre la política y la policía. Siempre he afirmado que con esos términos hago referencia a lógicas que se mezclan constantemente; ló- 
gicas que no diferencio en principio, excepto para comprender mejor las formas de su mezcla. Habiendo aclarado este aspecto, en términos generales podríamos considerar como "ética" a la comunidad basada sobre la negación de la contradicción. Desde este punto de vista la noción de comunidad educativa es claramente una noción ética. A ella subyace la idea de que el éxito de la educación depende de la constitución de cierto medio donde se optimizan las relaciones entre los agentes del proceso educativo. Esta visión de la comunidad educativa tiende, por un lado, a borrar la tensión entre las dos lógicas - igualitaria y desigualitaria - que habitan el corazón de los procesos de aprendizaje; y por otro lado, tiende a confirmar la lógica que estructura a la institución educativa, es decir, la puesta en acto de la idea de transmisión destinada a borrar la relación de exterioridad entre los actos intelectuales definidos por los términos "enseñar" y "aprender". Por supuesto, no me opongo al hecho de que los actores del sistema educativo reflexionen en conjunto sobre su práctica, pero esta reflexión debe llegar lo suficientemente lejos para incluir en sí misma el saber de esa contradicción, el saber de la separación entre las lógicas singulares designadas bajo el término "aprender" y los fines de la institución educativa como institución social que solemos aglutinar bajo el término "enseñar". En síntesis, esa reflexión debe ser capaz de asumir la parte de riesgo y transgresión que separa el hecho de aprender de toda planificación armoniosa de la transmisión de saberes.

¿Cuál puede ser, a tu entender, el rol de la filosofía en la educación y de la educación en la filosofía? ¿Consideras que el análisis de la separación de ambas esferas - filosofía y educación - comporta un elemento de importancia?

J.R.: Nuevamente desearía evitar definir la relación entre filosofía y educación como relaciones entre dos entidades estables y unívocas. Así como hay muchas maneras de pensar la actividad filosófica, también hay muchas maneras de comprender el significado de la palabra “educación.” Muy frecuentemente, nos situamos en el seno de nuestras instituciones educativas y nos preguntamos qué rol debemos otorgar a la filosofía en tanto que disciplina enseñada. Por esa vía obtenemos respuestas estereotipadas, como aquella según la cual la filosofía es esencial para desarrollar el "espíritu crítico." Desgraciadamente, este espíritu crítico es en sí mismo una categoría perfectamente integrada al universo intelectual dominante. Está claro que la filosofía ocupa en los sistemas educativos una posición de excepción, expresada particularmente por aquellos sistemas - como el francés - en los que la educación secundaria incluye a la filosofía. En tales sistemas tenemos, por un lado, departamentos de filosofía que forman profesores de filosofía y concursos que seleccionan a esos profesores. Pero por otro lado, tenemos una disciplina en la que resulta difícil definir el éxito de un aprendizaje en términos de conocimiento comprobable. En ese sentido, la filosofía puede ser entendida como el lugar donde la evidencia del proceso educativo entendido como transmisión de un saber (de alguien

Educação \& Realidade, Porto Alegre, v. 41, n. 2, p. 613-627, abr./jun. 2016. 
La Igualdad en la Revuelta Educativa

que sabe a alguien que ignora) se confiesa problemática. Solemos tomar de buen grado la imagen del filósofo cuestionador, ya sea a la manera de Sócrates o a la manera de Heidegger. Incluso podemos a suscribir a la imagen ofrecida por Calicles, la del viejo niño amante de los discursos cuya belleza radica en su marginalidad con respecto a toda función social $^{15}$. En lo que a mí concierne, pienso a la filosofía como el lugar donde se encuentra problematizada la separación entre el acto de enseñar y el acto de aprender; separación que abre una distancia que todo sistema educativo busca ocultar tras la evidencia de la "transmisión" del saber. Todo esto introduce una disociación en el interior de la práctica de la filosofía: por un lado, ocupamos un lugar definido en un sistema, pero por otro lado, realizamos un trabajo de pensamiento que pone en cuestión la distribución de los lugares de ese sistema. Enseñamos filosofía y, sin embargo, mantenemos su carácter in-enseñable. Este carácter no debe considerarse como un privilegio disciplinar, sino más bien como un ejercicio de pensamiento común que, desafiando las fronteras mediantes las cuales las disciplinas aseguran su transmisión y su reproducción, pone en cuestión tales privilegios.

En los bordes de lo político ${ }^{16}$ te detienes en el análisis de lo que denominas scholé. Caracterizas a la scholé como una forma simbólica a través de la cual las sociedades aristocráticas separaban un tiempo sustraído de las necesidades del orden productivo y distinguian a los seres capaces de hacer un uso libre del tiempo - condición de la participación en la vida política de la comunidad - de los seres incapaces de hacerlo por estar sumidos en la satisfacción de sus necesidades materiales. Planteas que la democracia opera una distorsión en la forma de la scholé. Esa distorsión consiste en vulgarizar el privilegio del tiempo libre o, en otras palabras, afirmar la capacidad de cualquiera de hacer un uso libre del tiempo. De modo que, según postulas, la escuela de la democracia, en tanto heredera paradójica de la scholé aristocrática, no iguala por la universalidad del saber que transmite, ni por sus efectos redistributivos, sino porque su forma misma constituye un lugar de visibilidad simbólica y empírica de la igualdad. ¿En qué sentido puede pensarse ese aspecto igualitario de la scholé? Y en este marco, ¿cómo caracterizarías el concepto de "escuela democrática"?

J.R.: Evidentemente no hay una caracterización simple de la scholé. En una época me aboqué a cuestionar la interpretación dominante - inspirada en el pensamiento de Pierre Bourdieu - que hacía de la escuela pública moderna una heredera de la distinción aristocrática. Para ello, me propuse mostrar que en la institucionalización y la generalización del tiempo de la scholé había una ruptura de la lógica tradicional, lógica que oponía dos humanidades oponiendo dos usos de tiempos. En el corazón de la modernidad política y artística yace la lucha contra ese antiguo reparto del tiempo. De hecho, resulta destacable que la institución de las esferas separadas (la escuela, el arte, etc.) contribuye a quebrar las antiguas separaciones. Es en este marco que afirmé que los efectos democráticos de la "separación" escolar eran más importantes que 
los efectos relativos a la distribución de saberes. De esta manera, tomé distancia de las tesis extendidas en Francia - vinculadas a la ideología denominada "republicana" - que identifican la separación escolar con la institución de un lugar puro de transmisión de saber, del cual la igualdad sería su resultado.

Por mi parte recuperé dos cuestiones. En primer lugar, la forma de la transmisión escolar no es más que una de las formas mediante las cuales el saber se adquiere. Hay una multitud de formas de adquisición que no siguen el modelo del vínculo profesor-estudiante. En segundo lugar, la escuela es una institución social, por lo tanto una institución atravesada por la tensión entre diversas funciones: transmite saberes y prepara para exámenes; constituye un marco de socialización de niños que pueden pertenecer a universos culturales y sociales diferentes; es una forma de gestión del tiempo global de una sociedad; además de otras cosas. No hay una escuela democrática pura porque no hay un principio unitario que unifique todas esas funciones en una lógica única. Desde este punto de vista, creo que debemos distinguir a aquellos que buscan realizar la igualdad en la escuela por la pura distribución igualitaria de saberes, de aquellos que quieren realizarla por medidas específicas destinadas a los niños de clases desfavorecidas ${ }^{17}$.

La escuela se encuentra atravesada por lógicas igualitarias y lógicas desigualitarias, sean propias de los saberes enseñados, de las formas de relación pedagógica, de las relaciones entre los niños o de las estrategias de sus padres. Una práctica igualitaria en la escuela es una práctica que busca permitir a la mayor cantidad posible de personas aprender de múltiples formas y tomar conciencia de la igual capacidad de las inteligencias. Pero es también una práctica consciente del hecho de que la escuela hace siempre muchas cosas a la vez, y que estas cosas son eventualmente contradictorias. Finalmente, debe quedar claro que uno aprende a lo largo de toda su vida en muchos otros lugares y tiempos totalmente distintos a los de la institución escolar.

Buena parte de tu obra apunta a desmantelar uno de los tópicos fundamentales de la tradición marxista y sus sucedáneos: la contraposición entre la "apariencia" política y la "realidad" social que la desmiente. Tu trabajo busca resignificar la "apariencia" política de la igualdad en el orden social. La política, según planteas, consiste en verificar esas inscripciones de igualdad a través de actos y discursos, y no en denunciar su falta de coincidencia con los hechos. Recuperando la noción de scholé y su herencia paradójica, ¿podemos postular una "escuela democrática" entendida como la inscripción de la igual capacidad de cualquiera de sustraerse del orden productivo? ¿Tal idea de "escuela democrática" puede interpretarse a la luz de la noción foucaultiana de heterotopía ${ }^{18}$ ?

J.R.: Seguramente también sea necesario superar la visión que incesantemente opone la apariencia de igualdad a la realidad de la desigualdad en lo relativo a la escuela. Sin embargo, eso no significa que pueda considerarse a la escuela sin más como un lugar heterotópico donde la 
La Igualdad en la Revuelta Educativa

igualdad encontraría su espacio propio de despliegue. Por un lado, la "separación" del lugar escolar es, a pesar de todo, muy relativa. Se trata de un sitio pesadamente determinado - y sobredeterminado - por el estatus que se le concede en el imaginario social y en las estrategias gubernamentales. Ahora bien, si dejamos de lado el esquema topográfico que opone la apariencia de igualdad a la realidad profunda de la desigualdad, lo hacemos para encontrar el lazo entre la lógica de verificación de la igualdad y la lógica de verificación de la desigualdad, es decir, el vínculo que une a una con la otra en el corazón mismo del proceso educativo. La "separación" de la escuela se constituye en un laboratorio privilegiado de experimentación de la lógica que pretende "partir" de la desigualdad para llegar a la igualdad. Hay una relación muy fuerte de homología entre la lógica de la institución escolar y la lógica social global de "verificación" de la desigualdad. Podemos detenernos a considerar la creación de zonas heterotópicas, sin embargo, debemos tener en cuenta que estas siempre pasarán por la realización de prácticas individuales de desviación.

Recibido en 20 de diciembre de 2015

Aprobado en 25 de febrero de 2016

Traducción: Nicolás Buchbinder y María Natalia Cantarelli (revisión técnica) ${ }^{19}$

\section{Notas}

1 Jacques Rancière (Argelia, 1940) es doctor en filosofía por la École Normale Supérieure. Es profesor emérito de la Universidad de París VIII Vicennes-Saint-Denis y profesor en la European Graduate School/EGS de Suiza. Agradecemos especialmente a Jacques Rancière el amable y atento gesto de ponerse a disposición de esta conversación que aloja nuestras inquietudes, surgidas del profundo impacto que ha tenido su pensamiento no sólo en nosotros sino también en la esfera de la reflexión filosófico-educativa argentina y latinoamericana.

2 El cuestionamiento que Rancière hace de la autoridad fundada en el saber desemboca en la postulación de la disociación entre la posición del maestro y la del sabio, y abre la posibilidad de pensar una figura magisterial por fuera de la autoridad institucional. Esta trayectoria conceptual puede rastrearse desde los textos más tempranos de Rancière, donde la filosofía de Louis Althusser y la sociología Pierre Bourdieu constituyen sus interlocutores polémicos, y su trasfondo fundamental son las revueltas obreras y estudiantiles del Mayo Francés.

3 Como hemos señalado, Rancière toma de Joseph Jacotot la idea de que la igualdad constituye un postulado práctico a ser declarado. En ese sentido, las declaraciones, lejos de ser ilusiones impotentes, tienen el poder que se le confiere, y ese poder es ante todo el de crear un sitio donde la igualdad pueda ser "verificada", es decir, traducida cotidianamente en actos y palabras que la desplacen. Ver Rancière (2007a, p. 72).

4 La "igualdad de la inteligencias" es una idea de Joseph Jacotot que Rancière hace suya. Jacotot constituye un interlocutor fundamental para el pensamiento de Rancière. Se trata de un pedagogo revolucionario francés del siglo XIX, creador

624 Educação \& Realidade, Porto Alegre, v. 41, n. 2, p. 613-627, abr./jun. 2016. 
de una pedagogía antimetódica, que distanciándose de la tradición ilustrada -según la cual la adquisición de conocimientos es condición para la libertad y la igualación de los hombres- denuncia que lejos de afianzar la igualdad, los emergentes sistemas educativos tienen por objeto cristalizar la diferencia entre sabios e ignorantes. Dicho de otro modo, la tiranía educativa - tal como la denomina- buscaría anular la experiencia primigenia de autonomía experimentada en el aprendizaje de la lengua materna (en el que no media explicación alguna). Esta capacidad es el factor sobre el cual Jacotot postula la igualdad de las inteligencias $\mathrm{y}$, a su vez, la que le permite poner en cuestión intuiciones tales como la necesidad de saber para enseñar y la de explicar para aprender. Ver, por ejemplo, Jacotot (2008).

5 Rancière (2014) (La méthode de l'égalité. Fayard, Paris, 2012).

6 Un claro ejemplo del establecimiento de este tipo de estándares de calidad, formulados en función de los intereses de los grandes capitales del "centro" o "norte", son las pruebas PISA (Programme for International Student Assessment).

7 En ese sentido, mirar/saber, apariencia/realidad, actividad/pasividad, son todo menos oposiciones lógicas entre términos bien definidos: definen propiamente un reparto de lo sensible, una distribución a priori de las posiciones y de las capacidades e incapacidades ligadas a dichas posiciones; son alegorías encarnadas de la desigualdad. La emancipación comienza cuando se cuestiona la oposición entre mirar y actuar, cuando se comprende que las evidencias que estructuran de esa manera las relaciones mismas del decir, el ver y el hacer pertenecen a la estructura de la dominación y de la sujeción; comienza cuando se comprende que mirar es también una acción que confirma o que transforma esa distribución de las posiciones. Cfr. Rancière (2010).

8 Rancière (2007b, p. 101-128) (Le maître ignorant. Paris: Favard, 1987).

9 Ver, por ejemplo, Deleuze (1987).

10 El término utilizado por Rancière aquí es skills. El término skills hace referencia a lo que en el campo educativo se conoce con el término "competencias" (noción proveniente del campo didáctico neo-liberal). Las competencias se basan mayormente en habilidades técnicas o destrezas prácticas objetivadas programáticamente y evaluadas como "aprendizajes comprobables" en un período de tiempo cronológicamente determinado. Íntimamente vinculada a la conocida "pedagogía por objetivos", la pedagogía por competencias responde directamente a las exigencias de la lógica de mercado que presupone un "sujeto incompetente" a "fabricar" como mano de obra competente en tal o cual área de conocimiento.

11 "Las cosas, entonces, estaban claras: no era un método para instruir al pueblo, era una buena nueva para anunciar a los pobres: podían todo aquello que puede un hombre. Sólo bastaba con anunciarla. Jacotot decidió consagrarse a esto. Proclamó que se puede enseñar lo que se ignora y que un padre de familia, pobre e ignorante, puede, si está emancipado, encargarse de la educación de sus hijos, sin el auxilio de ningún maestro explicador. Y señaló cuál era el medio para esta enseñanza universal: aprender cualquier cosa y relacionar todo el resto con ella, según este principio: todos los hombres tienen la misma inteligencia" (Rancière, 2007b, p. 34).

12 Rancière (1996) (La mésentente. Politique et philosophie. Paris: Galilée, 1995).

13 Rancière se esfuerza por distinguir a Jacotot de Sócrates, y para lograrlo evoca en múltiples ocasiones la escena del Menón, donde Sócrates conduce al esclavo 
La Igualdad en la Revuelta Educativa

de Menón en el descubrimiento de ciertas verdades matemáticas. Lejos de ser el servidor de Menón el que impulsa la búsqueda, es Sócrates quien la comanda. El esclavo acabaría conociendo, se afirma, si el maestro socrático siguiera interrogándolo (85d). No es casual que este aspecto se exprese en forma de condición. El acceso al conocimiento verdadero requiere un esfuerzo volitivo del que no todos son capaces (Platón, 2011a, 82a-85c.). A diferencia del metódico Sócrates, el esclavo depende de una conducción externa para remontar los saberes extraviados. De este modo, aunque la enseñanza conducida por Sócrates supone un camino de saber, se halla completamente desvinculada de toda emancipación. Vemos aquí un claro ejemplo de la tesis ranciereana que postula que el saber no conlleva efectos igualitarios.

14 Rancière (2011) (Malaise dans l'esthétique. Galilée: Paris, 2004).

15 Calicles es uno de los personajes principales del Gorgias de Platón. En tal diálogo, Calicles identifica a la filosofía como un elemento útil para la educación y señala que es una actividad adecuada para niños y jóvenes. Sin embargo, advierte que cuando esta actividad se extiende a la adultez, resulta ridícula y degradante (Platón, 2011b, 485a-c).

16 Rancière (2007a) (Aux bords du politique. La Fabrique: Paris, 1998).

17 En El maestro ignorante, Rancière tematiza la distinción entre estas dos aproximaciones al problema educativo. Allí las caracteriza a partir del debate que tuvo lugar en torno de la reforma del sistema educativo francés de la década del ochenta. En función de ello distingue, por un lado, a la pedagogía tradicional o republicana, ligada a la transmisión neutra y universal del saber como condición de la realización de la igualdad social; y por otro lado, a las pedagogías modernistas o críticas, que postulan la adaptación del saber al estado de la sociedad, formadas al calor de la sociología de Pierre Bourdieu.

18 Foucault señala que lo que habitualmente se denomina estructuralismo constituye un esfuerzo por establecer el conjunto de relaciones que configuran espacialmente ciertos elementos repartidos temporalmente. Desde esta perspectiva analiza la cuestión de las relaciones que definen los emplazamientos en el interior de los cuales viven los seres humanos. Dentro de la clasificación de los espacios que Foucault propone, existe un tipo de espacios, relacionados con todos los demás pero que a la vez los contradicen. Foucault los denomina "heterotopías" y define los principios de una disciplina que los estudia, la "heterotopología". Sintéticamente, los rasgos fundamentales de las heterotopías pueden definirse de la siguiente manera: los espacios heterotópicos se encuentran en la organización de todo grupo humano; éstos tienen el poder de yuxtaponer en un solo lugar real varios espacios o emplazamientos incompatibles entre sí; están habitualmente ligados a la definición de un período de tiempo; suponen, a su vez, algún sistema de cierre y apertura que define la circulación en su interior; y, finamente, cumplen algún tipo de función en la comunidad. Ver Foucault (1999, p. 431-441).

19 Quisiéramos agradecer a Nicolás Buchbinder el gesto de amistad de haber acompañado en la traducción de estos intercambios con Jacques Rancière en una lengua que no era nuestra pero que deja esta huella en medio del camino. Así también, y a la inversa, la relectura comprometida de Thomas Pages que se tomó la molestia de vérselas con los escritos en su lengua materna francesa y dar una revisión a la primera versión castellana que aquí presentamos con la mirada última a cargo de M. Natalia Cantarelli.

626 Educação \& Realidade, Porto Alegre, v. 41, n. 2, p. 613-627, abr./jun. 2016. 


\section{Referencias}

DELEUZE, Gilles. La Imagen-Tiempo. Estudios sobre cine 2. Buenos Aires: Paidós, 1987.

FOUCAULT, Michel. Espacios diferentes. In: FOUCAULT, Michel. Estética, Ética y Hermenéutica. Paidós: Barcelona, 1999. P. 431-441.

JACOTOT, Joseph. Lengua Materna. Enseñanza universal. Buenos Aires: Cactus, 2008. PLATÓN. Menón. Gredos: Madrid, 2011a, 82a-85c.

PLATÓN. Gorgias. Gredos: Madrid, 2011b, 485a-.

RANCIÈRE, Jacques. El Desacuerdo. Política y filosofía. Buenos Aires: Nueva Visión, 1996.

RANCIÈRE, Jacques. El Espectador Emancipado. España: Ellago Ediciones, 2010. P. 18-19.

RANCIÈRE, Jacques. En los Bordes de lo Político. Buenos Aires: Ediciones La Cebra, 2007a. P. 72.

RANCIÈRE, Jacques. El Maestro Ignorante. Cinco lecciones sobre la emancipación intelectual. Buenos Aires: Del Zorzal, 2007b. P. 101-128.

RANCIÈRE, Jacques. El Malestar en la Estética. Capital Intelectual: Buenos Aires, 2011. RANCIÈRE, Jacques. El Método de la Igualdad. Buenos Aires: Nueva Visión. 2014.

Facundo Giuliano es Investigador del Instituto de Investigaciones en Ciencias de la Educación - Facultad de Filosofía y Letras - Universidad de Buenos Aires.

E-mail: giulianofacundo@gmail.com

María Natalia Cantarelli es Investigadora del Instituto de Filosofía "Dr. Alejandro Korn” - Facultad de Filosofía y Letras - Universidad de Buenos Aires. E-mail: mariacantarelli@hotmail.com 